\title{
Nonspesifik Duodenitin Gastrit ve Helikobakter Pilori ile İlişkisi
}

\author{
Sebahattin Destek ${ }^{1}$, Vahit Onur Gül'징
}

'Bezmiâlem Vakıf Üniversitesi Tıp Fakültesi, Genel Cerrahi, İstanbul, Türkiye

${ }^{2}$ Gülhane Eğitim ve Araştırma Hastanesi, Genel Cerrahi, Ankara, Türkiye

Sebahattin Destek, 0p. Dr. Vahit Onur Gül, Op. Dr.

Iletişim:

Op. Dr. Vahit Onur Gül

Gülhane Eğitim ve Araştırma Hastanesi, Genel

Cerrahi, Ankara, Türkiye

Tel: +90 5323669227

E-Posta: vonurgul@hotmail.com
Gönderilme Tarihi : 09 0cak 2019

Revizyon Tarihi : : 06 Nisan 2019

Kabul Tarihi : : 07 Nisan 2019
ÖZET

Amaç: Duodenit, duodenum mukozanın inflamasyonu olup spesifik ve nonspesifik olarak ele alınır. Günümüzde nonspesifik duodenit (NSD) etyolojisinde Helikobakter pilorinin (H. pylori) etkisi hala netleşmemiştir. Bu çalışmamIzda, NSD patogenezinde H. pylori enfeksiyonunun önemi incelendi.

Hastalar ve Yöntem: Araştırmamızda, 2013-2016 yılları arasında, üst sindirim sistemi endoskopisi yapılan hastalar incelemeye alındı. NSD tanısı olan 137 hasta çalışmaya dahil edildi. Hastalara ait retrospektif dosyalardan, hastaların yaşı, cinsiyeti, gastrit durumu, mide mukozasında H. pylori varlığı, duodenit ve histopatolojik sonuçları veri olarak değerlendirilerek kayıt altına alındı.

Bulgular: Çalışmaya dahil edilen hastaların kadın/erkek oranı: 1/1 olup ortalama yaşları 41,9 yıl idi. Hastaların $\% 59,12$ ( $n=81$ )'sinde kronik gastrit; \%91,97 ( $n=126$ )'sinde kronik duodenit saptandı. Tüm hastaların \%58,39 ( $n=80$ )'unda mide mukozasında H. pylori saptandı. Aktif kronik duodenit bulunan hastaların \%90,91 ( $n=10$ )'inin mide mukozasında $\mathrm{H}$. pylori, \%72,73 ( $\mathrm{n}=8$ )'ünde ise aktif kronik gastrit tespit edilmiştir.

Sonuç: Çalışmamızda kronik duodenitin belirgin bir şekilde kronik gastrit ve H. pylori ile birlikte olduğu belirlenmiş olup, tetkik ve tedavi planlamalarında bu durumun göz önüne alınmasının hem hastanın tedavisi hem de tetkik etmek açısından kaynakların yerinde kullanımında önemli olabileceği kanaatindeyiz.

Anahtar sözcükler: Nonspesifik duodenit, gastrit, Helikobakter pilori

\section{THE RELATIONSHIP BETWEEN NONSPECIFIC DUODENITIS AND GASTRITIS WITH HELICOBACTER PYLORI}

\section{ABSTRACT}

Purpose: Duodenitis is the inflammation of the duodenal mucosa and is classified as specific and non-specific. Currently, the effect of Helicobacter pylori (H. pylori) in the etiology of nonspecific duodenitis (NSD) remains unclear. In this study, the importance of $H$. pylori infection in NSD pathogenesis was examined.

Patients and Methods: In our study, patients who underwent upper gastrointestinal endoscopy between 20132016 were included in the study. 137 patients with NSD were included in the study. Age, sex, gastritis status, presence of $\mathrm{H}$. pylori, duodenitis and histopathological results were recorded as data.

Results: The female / male ratio of the patients included in the study was $1 / 1$ and the mean age was 41.9 years. $59.12 \%(n=81)$ of the patients had chronic gastritis; $91.97 \%(n=126)$ had chronic duodenitis. In all patients, $58.39 \%(n=80)$ had H. pylori in the gastric mucosa. Of the patients with active chronic duodenitis, $90.91 \%(n=$ 10) had $H$. pylori in the gastric mucosa and $72.73 \%(n=8)$ had active chronic gastritis.

Conclusion: In our study, we found that chronic duodenitis was significantly associated with chronic gastritis and H. pylori. Considering this situation in the planning and treatment planning of patients, we believe that it can be important in the use of resources in terms of both treatment and examination of the patient.

Keywords: Nonspecific duodenitis, gastritis, Helicobacter pylori 
D uodenit, duodenal mukozanın epitel hasarı ve mukozal inflamasyonunu içerir (1). Duodenit klinik seyir açısından akut ve kronik olarak sınıflandırılır (2). Kronik duodenit ise primer (nonspesifik duodenit, NSD) ve sekonder (spesifik) olarak klinik formlara ayrılır (2). Dünya Sağlık Örgütü (WHO) ICD-10 Versiyon: 2015'de gastrit ve duodenit başlığı altında gastrit ve duodeniti birlikte incelemiştir (3). Ancak, WHO ICD-11 Versiyon: 2018'de ise gastrit ve duodeniti ayrı başlıklarda sınıflandırmıştır (3).

Duodenit, endoskopik ve histopatolojik olarak tanı konulur $(1,4)$. Endoskopik biyopsi örneklerinin histopatolojik olarak incelemesi, duodenal patolojilerin ayırıc tanısında esastır $(2,4)$. Duodenit, yüksek asit sekresyonu, viral, bakteriyel ve parazitik enfeksiyöz ajanlar, ilaçlar, kimyasal ajanlar, alerjenler, otoimmünite gibi çeşitli faktörlerden kaynaklanır $(2,4)$.

1983'de keşfedilen Helikobakter pilori (H. pylori ), insandan insana bulaşabilmekte ve dünya nüfusunun neredeyse yarısında bulunmaktadır (5). H. pylori, gastrit, peptik ülser hastalığı, mide mukoza ilişkili lenfoid doku lenfoma ve mide adenokarsinomu gibi gastrik; demir eksikliği anemisi, idiyopatik tromobositopenik purpura ve bazı hastalarda koroner arter hastalığı gibi gastrik olmayan birçok hastalıkta aktif rol oynar $(6,7)$.

Son çalışmalar, gastrik patolojilerin duodenumu da etkileyebileceğini göstermiştir (2). H.pylori, gastrik mukoza epitelinde kolonize olarak duodenit için zemin hazırlayabilir $(1,7)$. Bu nedenle, duodenal patolojisi olan hastaların midelerinden de örnek alınması önerilmektedir $(2,6)$.

Bu çalışmamızda NSD, gastrit ve H. pylori arasındaki ilişkiye bakılarak NSD patogenezinde $H$. pylori enfeksiyonunun rolünün incelenmesi amaçlanmıştır.

\section{Gereç ve Yöntem}

Bu çalışmamızda, 2013-2016 yılları arasında hastanemizin endoskopi biriminde üst sindirim sistemi endoskopisi yapılan hastalar incelemeye alındı. Yapılan retrospektif dosya taramasında, dispeptik şikayetleri nedeniyle üst sindirim sistemi endoskopisi yapılan 164 hastadan hem mide hem de duodenum biyopsisi alındığı belirlendi. Malignite, çölyak hastalığı, polipod lezyon gibi ek tanısı olan ya da verilerine ulaşılamayan hastalar çalışma dışı bırakılarak çaış̧maya dahil edilmedi. NSD tanısı olan 137 hasta çalışmaya alındı. Çalışmaya dahil edilen bu hastaların yaşı, cinsiyeti, mide ve duodenum mukozasından alınan biyopsilerin histopatolojik özellikleri, gastrit durumu, mide mukozasında $H$ pylori varlığı ve duodenit durumu değerlendirildi.
Histolojik inceleme için \%10 formalinle sabitlenmiş biyopsi örnekleri rutin doku takip işlemi sonrası, parafin bloklara gömülen örneklerden $4 \mu \mathrm{m}$ (mikron) kalınlığında seri kesitler alınmıştır. Deparafinize edilen doku kesitlerinin histolojik incelemesi için hematoksilen-eozin ile $\mathrm{H}$. pylori varlığının değerlendirilmesi için de giemsa ile boyandı. Preparatlar ışık mikroskopisinde deneyimli tek bir patolog tarafından incelendi. Kronik duedonit ve aktif kronik duedonit durumları, nonspesifik duodenit kapsamında değerlendirildi. Gastrik ve duodenal biyopsi örnekleri, güncellenmiş Sydney Sistemine göre değerlendirilerek (8) preperatlar H. pylori varlığı var/yok şeklinde değerlendirildi.

\section{Istatistiksel analiz}

İstatistiksel çalışma için veriler, lisanlı SPSS 21 paket programı (IBM Corp., Armonk, NY, USA) ile analiz edilmiştir. Gruplar arasındaki farklılıklar incelenirken değişkenlerin normal dağılımdan gelmemesi durumunda Mann Whitney $U$ testinden yararlanılmıştır. Nominal değişkenlerin grupları arasındaki ilişkiler incelenirken Ki-Kare analizi uygulanmıştır. $2 \times 2$ tablolarda gözelerdeki beklenen değerlerin yeterli hacme sahip olmaması durumlarında Fisher's Exact Test kullanılmış olup RxC tablolarda ise Monte Carlo Simülasyonu yardımıyla Pearson Ki-Kare analizi uygulanmıştır. Sonuçlar yorumlanırken anlamlılık düzeyi olarak 0,05 kullanılmış olup; $p<0,05$ olması durumunda anlamlı bir farklılığın olduğu, $p>0,05$ olması durumunda ise anlamlı bir farklılığın olmadığı belirtilmiştir.

\section{Bulgular}

Çalışmaya dahil edilen hastaların \%51,82 ( $\mathrm{n}=71)$ 'si kadın olup kadın/erkek oranı: 1/1'dir. Yaş aralığı 14-85 yıl olup ortalama yaş 41,9 yıl idi. Hastaların \%59,12 ( $\mathrm{n}=81$ )'sinde kronik gastrit; \%91,97 ( $n=126)$ 'sinde kronik duodenit saptandı. Yapılan incelemede tüm hastaların \%58,39 ( $n=80)^{\prime}$ unda mide mukozasında HP saptandı (Tablo 1).

Çalışmamızda NSD tipleri ile gastrit durumları arasında istatistiksel olarak anlamlı bir fark bulunmaktadır $(p=0,025)$. Kronik duodenit tanısı koyulan hastaların \%61,9 $(\mathrm{n}=78)^{\prime}$ unun kronik gastrit tanısı olduğu, aktif kronik duodenit tanısı koyulan hastaların da \%72,73 ( $n=56$ )'ünde aktif kronik gastrit tanısı konmuştur (Tablo 2).

NSD tipleri ile mide mukozasında H. pylori var/yok durumları arasında istatistiksel olarak anlamlı bir fark bulunmaktadır $(p=0,023)$. Kronik duodenit tanısı koyulan hastaların \%55,56 ( $\mathrm{n}=70$ )'sında mide mukozasında H. pylori varken, aktif kronik duodenit tanısı koyulan hastaların \%90,91 ( $\mathrm{n}=10$ )'inin mide mukozasında H. pylori vardır (Tablo 2). 
Tablo 1. Demografik ve patolojik parametrelerin dağılım

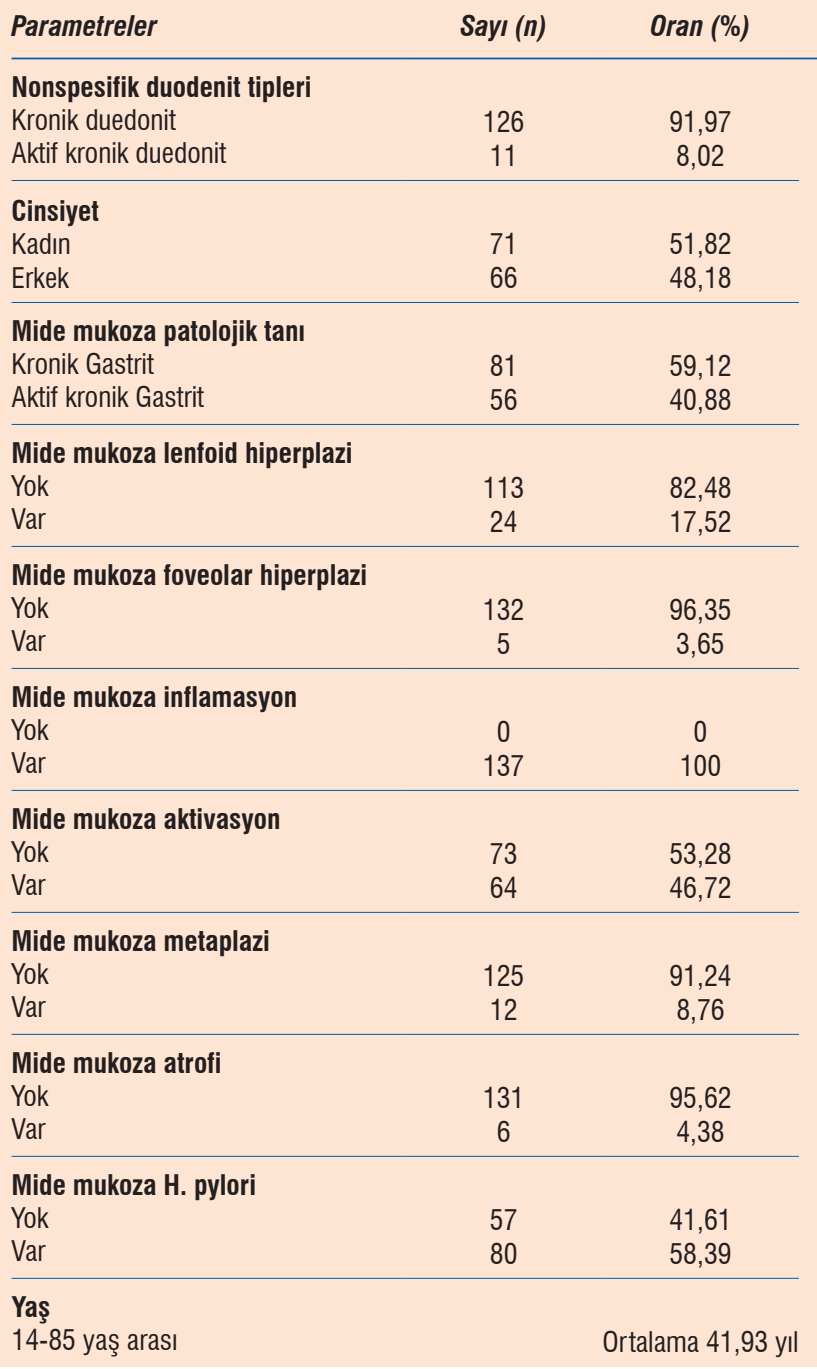

NSD tipleri ile diğer değişkenler arasında istatistiksel olarak anlamlı bir fark bulunmamaktadır $(p>0,05)$. Yaş ile NSD arasında istatistiksel olarak anlamlı bir farklılık bulunmamaktadır $(p>0,05)$. Anlamlı olmamakla birlikte, kronik duodenit tanısı koyulan hastaların yaş değerleri daha yüksektir (Tablo 2).

\section{Tartışma}

Duodenum mukozasının uzun süreli epitel hasarı ve mukozal inflamasyonuyla oluşan kronik duodenit, genellikle duodenumun ilk kısmında görülür (1). Kronik duodenit primer (NSD) olabildiği gibi crohn hastalığı, sarkoidoz gibi hastalıklara bağlı olarak sekonder (spesifik) olarak da görülebilir $(2,9)$.

NSD, duodenum ülserasyonuna eşlik edebilen veya ayrı bir hastalık olarak bulunabilen yaygın bir durumdur $(2,4)$.
Bazı araştırmacılar, NSD'nin duodenal ülser hastalığının bir evresi olduğunu da söylemişlerdir $(2,10)$.

Günümüzde hala NSD'nin etyolojisi tam olarak açıklanamamıştır. Etyolojide ağılıklı olarak gastrik asit fazlalığı ve H. pylori üzerinde durulmaktadır $(2,11,12)$. Ayrıca, midede H. pylori ve gastrit metaplazi olduğunda kronik duodenitin daha fazla görüldüğü bildirilmiştir $(2,12)$. Bunun dışında toksik diyet bileşenleri, etanol, non-steroid antiinflamatuar ilaçların da etyolojide rol aldığı üzerinde durulmaktadır (2).

Araştırmalarda $H$. pylori ile enfekte olan hastaların $\% 82,2$ 'sinde duodenit tespit edildi (12). Ancak, buna karşın bazı araştırmalarda da bunu aksi söylenerek NSD'nin etyolojisinde H. Pylori'nin söylendiği kadar çok etkili olmadığı belirtilmiştir (14-16). Diğer taraftan yüksek prevalans bölgelerinde $H$. Pylori'nin duodenite katkıda bulunan başlıca faktör olabileceği de bildirilmiştir (16).

H. pylori, dünya çapında en sık görülen bakteriyel enfeksiyon olması ve neden olduğu hastalıklar açısından önemli bir sağlık sorunudur (5). Yaklaşık olarak dünya nüfusunun $\% 50$ 'den fazlasının $H$. pylori ile enfekte olduğu bildirilmekte ve bu enfekte kişilerin \%10-20'si semptomatik hale gelmektedir (6). Kaynağı sadece insan olan ve insandan başka herhangi bir kaynaktan izole edilemeyen $H$. pylori, midede korpus, kardiya ve antrum distalinde yaşamını sürdürmektedir $(5,6)$. Türkiye'de yapılan çalışmalarda $H$. pylori prevalansının \%82,5'lere çıktığı bildirilmiştir $(17,18)$.

Düşük sosyoekonomik durum ve kalabalık yaşam koşulları H. pylori enfeksiyonu açısından risk faktörleridir. Bu ve benzeri koşullarda yaşayan kişilerde $H$. pylori enfeksiyonunun daha sık görülmesi fekal-oral yolla bulaş ihtimalini düşündürmektedir (19). Ülkemizin batısında H. pylori daha az görülürken; doğusunda belirgin bir artış dikkati çekmektedir. Bunun nedenleri arasında, bölgemizin sosyokültürel bakımdan nispeten geri olması, çevresel faktörler, sağlık bilgisi eksikliği, H. pylori eradikasyon tedavisinin daha az verilmiş olması gösterilebilir (20). Bizim çalışmamızda, Marmara bölgesinde yapılmış olup, H. pylori görülme oranı \%58,39 olarak tespit edildi. Genel olarak bakıldığında Türkiyede $H$. pylori görülme oranı \%50'nin üzerindedir.

Çalışmamızda kronik duodenit ile kronik gastrit arasında istatistiksel olarak anlamlı bir ilişki saptanmıştır. Ayrıca NSD ile mide mukozasında $H$. pylori varlığı arasında istatistiksel olarak anlamlı bir fark bulunmuştur. Kronik duodenit tanısı koyulan hastaların \%55,56'sında; aktif kronik 
Tablo 2. Nonspesifik duodenit ile parametreler arasındaki ilişki

\begin{tabular}{|c|c|c|c|c|c|c|c|c|}
\hline \multirow[t]{2}{*}{ Parametreler } & \multicolumn{2}{|c|}{ Kronik } & \multicolumn{2}{|c|}{ Aktif Kronik } & \multicolumn{2}{|c|}{ Kronik + Aktif Kronik } & \multicolumn{2}{|c|}{ Ki-kare testi } \\
\hline & $n$ & $\%$ & $n$ & $\%$ & $n$ & $\%$ & Ki-Kare & $p$ \\
\hline \multicolumn{9}{|l|}{ Gastrik patolojik tanı } \\
\hline Kronik Gastrit & 78 & 61,9 & 3 & 27,27 & 81 & 59,12 & \multirow{2}{*}{5,021} & \multirow{2}{*}{0,025} \\
\hline Aktif Kronik Gastrit & 48 & 38,1 & 8 & 72,73 & 56 & 40,88 & & \\
\hline \multicolumn{9}{|l|}{ Cinsiyet } \\
\hline Kadın & 68 & 53,97 & 3 & 27,27 & 71 & 51,82 & \multirow{2}{*}{2,888} & \multirow{2}{*}{0,089} \\
\hline Erkek & 58 & 46,03 & 8 & 72,73 & 66 & 48,18 & & \\
\hline \multicolumn{9}{|c|}{ Mide mukoza lenfoid hiperplazi } \\
\hline Yok & 106 & 84,13 & 7 & 63,64 & 113 & 82,48 & \multirow{2}{*}{1,693} & \multirow{2}{*}{0,193} \\
\hline Var & 20 & 15,87 & 4 & 36,36 & 24 & 17,52 & & \\
\hline \multicolumn{9}{|c|}{ Mide mukoza foveolar hiperplazi } \\
\hline Yok & 121 & 96,03 & 11 & 100 & 132 & 96,35 & \multirow{2}{*}{$\mathrm{f} \neq$} & \multirow{2}{*}{0,654} \\
\hline Var & 5 & 3,97 & 0 & 0 & 5 & 3,65 & & \\
\hline \multicolumn{9}{|c|}{ Mide mukoza inflamasyon } \\
\hline Yok & 0 & 0 & 0 & 0 & 0 & 0 & \multirow{2}{*}{-} & \multirow{2}{*}{-} \\
\hline Var & 126 & 100 & 11 & 100 & 137 & 100 & & \\
\hline \multicolumn{9}{|c|}{ Mide mukoza aktivasyon } \\
\hline Yok & 70 & 55,56 & 3 & 27,27 & 73 & 53,28 & \multirow{2}{*}{3,251} & \multirow{2}{*}{0,071} \\
\hline Var & 56 & 44,44 & 8 & 72,73 & 64 & 46,72 & & \\
\hline \multicolumn{9}{|c|}{ Mide mukoza metaplazi } \\
\hline Yok & 115 & 91,27 & 10 & 90,91 & 125 & 91,24 & \multirow{2}{*}{0,002} & \multirow{2}{*}{0,968} \\
\hline Var & 11 & 8,73 & 1 & 9,09 & 12 & 8,76 & & \\
\hline \multicolumn{9}{|l|}{ Mide mukoza atrofi } \\
\hline Yok & 120 & 95,24 & 11 & 100 & 131 & 95,62 & \multirow{2}{*}{0,548} & 0459 \\
\hline Var & 6 & 4,76 & 0 & 0 & 6 & 4,38 & & 0,459 \\
\hline Mide mukoza H. pylo & & & & & & & & \\
\hline Yok & 56 & 44,44 & 1 & 9,09 & 57 & 41,61 & 5205 & 0023 \\
\hline Var & 70 & 55,56 & 10 & 90,91 & 80 & 58,39 & $\checkmark, \angle \cup \checkmark$ & $0,0<v$ \\
\hline & & & Nonspesifi & denit Tip & & & Mann WI & U Testi \\
\hline & $n$ & Mean & Median & Min & Max & SS & $z$ & $p$ \\
\hline Yaş & & & & & & & & \\
\hline Kronik Duodenit & 126 & 42,2 & 38,5 & 14 & 85 & 16,97 & -0.677 & 0.498 \\
\hline Aktif Kronik Duodenit & 11 & 38,91 & 33 & 23 & 67 & 14,83 & 0,067 & 0,700 \\
\hline
\end{tabular}

duodenit tanısı koyulan hastaların da \%90,91'inin mide mukozasında $H$. pylori tespit edilmiştir. Bu da $H$. pylori ile NSD arasında bariz bir ilişki olduğunu ortaya koymaktadır.

\section{Sonuç}

Tedaviye rağmen devam eden dispeptik şikayetlerin varlığında $H$. pylori varlığı araştırılması gerektiği düşünülmelidir. Aynı zamanda H. pylori varlığında sadece midenin değil; beraberinde duodenumunda etkilendiğini ve NSD oluşabileceğini, tedavi ve takiplerde buna dikkat edilmesininde yararlı olabileceğinin akla getirilmesi oldukça önemlidir. Böylece hem tedavi başarısını artırılması sağlanabilir hem de kaynaklar uygun ve yerinde kullanılmış olabilecektir. 


\section{Kaynaklar}

1. Taş A, Koklu S, Beyazit $Y$, et al. The endoscopic course of scattered white spots in the descending duodenum: a prospective study. Gastroenterol Hepatol. 2012;35:57-64. [CrossRef]

2. Wang CX, Liu LJ, Guan J, Zhao XL. Ultrastructural changes in nonspecific duodenitis. World J Gastroenterol. 2005;11:686-9. [CrossRef]

3. http://id.who.int/icd/entity/1595026136 (18 June 2018)

4. Konorev MR, Litviakov AM, Matveenko ME, et al. Principles of current classification of duodenitis. Klin Med (Mosk). 2003; 81:15-20.

5. Moayyedi P. The health economics of Helicobacter pylori infection. Best Pract Res Clin Gastroenterol. 2007;21:347-61. [CrossRef]

6. Sugano K, Tack J, Kuipers EJ, et al. Kyoto global consensus report on Helicobacter pylori gastritis. Gut 2015;64:1353-67. [CrossRef]

7. Suzuki H, Franceschi F, Nishizawa T, Gasbarrini A. Extragastric manifestations of Helicobacter pylori infection. Helicobacter. 2011;16:65-9. [CrossRef]

8. Sipponen P, Price AB. The Sydney System for classification of gastritis 20 years ago. J Gastroenterol Hepatol. 2011;26 Suppl 1:31-4. [CrossRef]

9. Mirbagheri SA, Khajavirad N, Rakhshani N, et al. Impact of Helicobacter pylori infection and microscopic duodenal histopathological changes on clinical symptoms of patients with functional dyspepsia. Dig Dis Sci. 2012;57:967-72. [CrossRef]

10. Kreuning J, vd Wal AM, Kuiper G, Lindeman J. Chronic nonspecific duodenitis. A multiple biopsy study of the duodenal bulb in health and disease. Scand J Gastroenterol Suppl. 1989;167:16-20.

11. Peura DA, Malfertheiner P. Chairmen's summary: dichotomies and directions in acid-related disorders. Aliment Pharmacol Ther. 2004;19:77-80.
12. Voutilainen $M$, Juhola $M$, Färkkilä M, Sipponen P. Gastric metaplasia and chronic inflammation at the duodenal bulb mucosa. Dig Liver Dis. 2003;35:94-8.

13. Caselli M, Gaudio M, Chiamenti CM, et al. Histologic findings and Helicobacter pylori in duodenal biopsies. J Clin Gastroenterol. 1998;26:74-80.

14. Hsu CT, Yeh C, Cheng HH. Helicobacter pylori, gastritis and duodenitis in the healing process of duodenal ulcer. J Formos Med Assoc. 1992;91:81-4.

15. Carmack SW, Genta RM. The diagnostic value of the duodenal biopsy: a clinico-pathologic analysis of 28,000 patients. Dig Liver Dis. 2010; 42:485-9. [CrossRef]

16. Sahin A, Cihangiroglu G, Bilgic $Y$, Calhan T, Cengiz M. Is duodenal biopsy appropriate in areas endemic for Helicobacter pylori?. North Clin Istanb. 2017;4:13-21. [CrossRef]

17. Ozdil K, Sahin A, Kahraman R, et al. Current prevalence of intestinal metaplasia and Helicobacter pylori inf ection in dyspeptic adult patients from Turkey. Hepatogastroenterology. 2010;57:1563-6.

18. Ozaydin N, Turkyilmaz SA, Cali S. Prevalence and risk factors of Helicobacter pylori in Turkey: a nationally-representative, crosssectional, screening with the ${ }^{13} \mathrm{C}$-Urea breath test. BMC Public Health. 2013;13:1215. [CrossRef]

19. Alim A, Ataş $A D$, Güneş T, ve ark. Sivas ili merkezinde semptomatik ve asemptomatik yetişkin bireylerde Helicobacter pylori seroprevalansı. CÜ Tıp Fak Derg 2004;26:75- 80.

20. Demirtas L, Ilyas Sayar I, Akbas EM ve ark. Endoskopi yapılan hastalarda Helicobacter pylori sıklığı ve yerleşim yerinin yaş ve cinsiyete göre dağııımı. Dicle Med J. 2014;41: 507-11. [CrossRef] 